\title{
Naloxone blockade of amphetamine place preference conditioning *
}

\author{
Keith A. Trujillo ${ }^{1,2}$, James D. Belluzzi ${ }^{1}$, and Larry Stein ${ }^{1}$ \\ ${ }_{1}^{1}$ Department of Pharmacology, University of California, Irvine, CA 92717, USA \\ ${ }^{2}$ Mental Health Research Institute, The University of Michigan, 205 Washtenaw Place, Ann Arbor, MI 48109-0720, USA \\ Received May 11, 1990 / Final version August 10, 1990
}

\begin{abstract}
Amphetamine and naloxone were examined in place conditioning, in order to study possible interactions between endogenous opioids and catecholamines in reinforcement. After initial preferences were determined, animals were conditioned with amphetamine alone $(1.0 \mathrm{mg} / \mathrm{kg} \mathrm{SC})$, naloxone alone $(0.02,0.2$ or $2.0 \mathrm{mg} / \mathrm{kg} \mathrm{SC}$ ) or combinations of amphetamine plus naloxone. A reliable, long-lasting preference for the compartment associated with amphetamine was observed, reflecting the reinforcing properties of this drug. No preference or aversion was observed in animals that received saline in both compartments. Naloxone $(0.02$, 0.2 and $2.0 \mathrm{mg} / \mathrm{kg}$ ) produced a dose-dependent place aversion; while the lowest dose had effects similar to saline, the higher doses produced significant place aversions. Naloxone, at all three doses examined, prevented the ability of amphetamine to produce a place preference. Thus, the lowest dose of naloxone, having no effects alone in place conditioning was still able to block the reinforcing effects of amphetamine. These results suggest that the reinforcing effects of amphetamine are dependent on activation of opiate receptors, and provide further evidence that interactions between endogenous opioids and catecholamines may be important in reinforcement.
\end{abstract}

Key words: $d$-Amphetamine - Naloxone - Place conditioning - Conditioned place preference - Reward - Reinforcement - Endogenous opioids - Catecholamines

Evidence suggests that two types of neurotransmitter, catecholamines and endogenous opioids, may be important in the rewarding actions of drugs of abuse and other stimuli (Stein 1978; Watson et al. 1989). Catechol-

* A preliminary report of this research was presented at the 11 th Annual Society for Neuroscience Meeting in Dallas, Texas (Trujillo et al. 1985)

Offprint requests to: K.A. Trujillo ${ }^{2}$ amines, particularly dopamine, appear to mediate the reinforcing properties of the psychomotor stimulants amphetamine and cocaine, while opiate drugs produce reinforcement by mimicking the actions of endogenous opioids at opioid receptors. Additionally, studies suggest that opioids and catecholamines, and the drugs that affect these systems, may interact in reward processes. Depletion of catecholamines with alpha-methyl paratyrosine prevents self-administration of morphine (Davis and Smith 1973) and suppresses the potentiating effects of morphine on self-stimulation (Pert and Hulsebus 1975). Dopamine receptor antagonists have been observed to block the reinforcing actions of opiates in place preference conditioning (Bozarth and Wise 1981; Phillips et al. 1982; Spyraki et al. 1983; Shippenberg and Herz 1987; Hand et al. 1989; however see also Mackey and van der Kooy 1985). Synergistic effects have been observed on self-stimulation behavior when morphine and amphetamine are injected together, suggesting a potent interaction between these compounds in reinforcement (Hubner et al. 1987). The opioid receptor antagonist naloxone blocks the facilitation of rate (Holtzman 1976; Franklin and Robertson 1982; Trujilo et al. 1983) and the decrease in threshold (Esposito et al. 1980) produced by amphetamine in self-stimulation and potentiates the threshold-increasing effects of chlorpromazine (Esposito et al. 1981). More recently, opiate antagonists have been found to block the cocaine-induced decrease in self-stimulation threshold (Bain and Kornetsky 1986) and to alter the self-administration of cocaine in a manner consistent with a decrease in reinforcement (Carroll et al. 1986; De Vry et al. 1989). It thus appears that opioids and catecholamines interact in positive reinforcement, and it may well be that there is an interdependence of these neurotransmitter systems in reward function (Belluzzi and Stein 1977; Maroli et al. 1978; Broekkamp et al. 1979; Bozarth and Wise 1981; Esposito et al. 1981; Bozarth 1983; Bain and Kornetsky 1986; Watson et al. 1989).

The place conditioning paradigm has attracted considerable attention in recent years as a valuable method 
for assessing the reinforcing actions of drugs (see Bozarth 1987; van der Kooy 1987; Carr et al. 1989; Hoffman 1989 for reviews). In this paradigm, administration of a drug is paired with a distinct set of environmental cues during conditioning trials. The reinforcing or aversive properties of the drug are determined by assessing whether the subject approaches or avoids the drugpaired environment after conditioning. The place conditioning paradigm has been useful in examining the reinforcing properties of opiate drugs (Rossi and Reid 1976; Bozarth and Wise 1981; van der Kooy et al. 1982; Shippenberg and Herz 1987; Shippenberg et al. 1988, 1989), opioid peptides (Katz and Gormenzano 1979; Stapleton et al. 1979; Phillips and LePiane 1982; Glimcher et al. 1984a; Almaric et al. 1987), and psychomotor stimulants (Reicher and Holman 1977; Sherman et al. 1980; Spyraki et al. 1982a, b; Gilbert and Cooper 1983), as well as a variety of other compounds (Glimcher et al. 1984a, b; Fudala et al. 1985; Spyraki et al. 1985; File 1986). In addition, this method has proven valuable in studying interactions between drugs and the neurotransmitter systems they affect (Bozarth and Wise 1981; Spyraki et al. 1982a, b; 1983; 1987; 1988; Carboni et al. 1989; Houdi et al. 1989).

In the present studies, amphetamine and naloxone were examined alone and in combination in place conditioning, in order to determine possible interactions between endogenous opioids and catecholamines in reinforcement.

\section{Materials and methods}

Animals. One hundred and forty-one experimentally naive, male, Sprague-Dawley rats (Charles River) were used. Animals weighed $250-350 \mathrm{~g}$ at the start of experiments, and were housed in groups of three to five in stainless steel cages on a $12 \mathrm{hlight/dark}$ cycle, with food and water avallable ad lib.

Apparatus. Two identical Plexiglas shuttle boxes $(80 \times 25 \times 30 \mathrm{~cm})$, divided into three distinct compartments, were used for experiments. The shuttle boxes had clear ceilings and consisted of two large compartments $(35 \times 25 \mathrm{~cm})$ separated by stainless steel guillotine doors from a smaller central compartment $(10 \times 25 \mathrm{~cm})$. One of the large compartments had black walls, a stainless steel grid floor, and sawdust litter below the floor; the other had white walls, a wire mesh floor, and corncob litter below the floor. The central compartment had one black wall containing a $9 \mathrm{~cm}$ wide opening into the black compartment, one white wall containing a $9 \mathrm{~cm}$ wide opening into the white compartment, and two gray walls; guillotine doors blocking the openings could be removed to allow the animal access to the entire shuttle box. A microswitch mounted beneath the floor of each compartment detected when the animal was in that compartment. The number of entries into, and the amount of time spent within each compartment was automatically recorded by a computer interfaced with the shuttle boxes via a BRS-LVE Interact system. During experiments the testing room was dimly lit by fluorescent fixtures mounted on the ceiling. A single speaker positioned at the rear of the middle chamber delivered white noise.

Drugs. Drugs tested were $d$-amphetamine sulfate alone $(1.0 \mathrm{mg} / \mathrm{kg})$, naloxone $\mathrm{HCl}$ alone $(0.02,0.2$, and $2.0 \mathrm{mg} / \mathrm{kg})$, or combinations of amphetamine plus each of the three doses of naloxone, delivered in a single injection. Drugs were dissolved in sterile saline and administered subcutaneously $(S C)$ in a volume of $1.0 \mathrm{ml} / \mathrm{kg}$ immediately before placing the animal in the shuttle box.

General procedure. Animals were weighed and handled for at least 1 week prior to experiments. Experiments began with 3 or 4 preconditioning test days: each animal was placed in the central compartment and the guillotine doors immediately removed, giving the animal access to the entire shuttle box for $15 \mathrm{~min}$. The amount of time spent by each rat in the two large compartments on the final preconditioning day was used as a measure of initial preference. The following 8 days served as the conditioning phase: on alternate days each animal was injected with drug and confined to one of the large compartments, or injected with saline and confined to the opposite compartment, for $30 \mathrm{~min}$. The order of injection was counterbalanced across rats. Control animals received saline injections in both compartments. The final phase of the experiment was the postconditioning preference determination, and was identical to the preconditioning test days: each animal was placed in the central compartment (without injection) and again given access to the entire apparatus for $15 \mathrm{~min}$, during which the time spent in each compartment was automatically recorded. Throughout all phases of experiments, the black compartment was wiped thoroughly with a dilute ethanol solution, and the white compartment with a dilute soap solution immediately prior to exposing each animal to the shuttle box, in order to further distinguish these compartments; the central compartment was wiped clean with distilled water in order to remove the odor of the previous animal. The conditions of the shuttle boxes established a balanced choice situation for the rats. While each rat had an individual preconditioned bias for one compartment over the other, there was no bias for the group as a whole; half the rats preferred the white compartment and half preferred the black compartment at the beginning of experiments (see Results).

Experiment 1 procedure. Amphetamine place conditioning. Amphetamine place conditioning was examined in two studies. Experiment 1 a determined the ability of amphetamine to produce a preference for the initially non-preferred compartment, and compared these affects to those of saline. After the preconditioning preference determination, amphetamine-conditioned animals $(n=9)$ received, on alternate days, amphetamine in the initially non-preferred compartment or saline in the initially preferred compartment. Control animals $(n=7)$ received saline treatment in both compartments (the initially non-preferred compartment was designated as the drugpaired compartment for comparison with amphetamine-treated animals). Preference was determined on day 1 and on day 7 after conditioning. Experiment $1 \mathrm{~b}$ compared amphetamine conditioning in the initially non-preferred compartment with amphetamine conditioning in the initially preferred compartment. This comparison allows one to rule out certain non-specific factors, such as a non-contingent shift in preference, that might potentially be involved in place conditioning (Spyraki et al. 1985; Carr et al. 1989). After the preconditioning preference determination, one group of animals $(n=10)$ received amphetamine in the initially non-preferred compartment and saline in the initially preferred compartment, while a second group $(n=16)$ received amphetamine in the initially preferred compartment and saline in the initially non-preferred compartment, on alternate days. A third group $(n=8)$ received saline in both compartments (as above, the initially nonpreferred compartment was designated as the drug-paired compartment for comparison with amphetamine-treated animals).

Experiment 2 procedure. Naloxone place conditioning. This experiment examined the ability of naloxone to produce a conditioned place aversion. Following the preconditioning preference determination, animals ( $n=8$ per group) received, on alternate days, naloxone $(0.02,0.2$, or $2.0 \mathrm{mg} / \mathrm{kg})$ in the initially preferred compartment or saline in the initially non-preferred compartment. For comparison and control, a fourth group received naloxone $(2.0 \mathrm{mg} / \mathrm{kg})$ in the initially non-preferred compartment, and saline in the initial- 
ly preferred compartment. As noted above, this control group allows one to determine whether certain non-specific factors might play a role in the place conditioning experiment.

Experiment 3 procedure. Place conditioning with naloxone and amphetamine. Interactions between amphetamine and naloxone in place conditioning were examined in this experiment. In particular, we were interested in whether the opiate antagonist naloxone might interfere with the conditioned place preference produced by amphetamine. During conditioning, animals received amphetamine $(1.0 \mathrm{mg} / \mathrm{kg})$ and naloxone $(2.0 \mathrm{mg} / \mathrm{kg}, n=11 ; 0.2 \mathrm{mg} / \mathrm{kg}, n=8$; or $0.02 \mathrm{mg} / \mathrm{kg}, n=16$ ) administered together in a single injection in the initially non-preferred compartment, or saline administered in the initially preferred compartment, on alternate days. For comparison and control, a fourth group $(n=24)$ was conditioned with amphetamine $(1.0 \mathrm{mg} / \mathrm{kg})$ and naloxone $(0.02 \mathrm{mg} / \mathrm{kg})$ in the initially preferred compartment, alternated with saline in the initially non-preferred compartment

Data analysis. The difference between the amount of time spent in the drug-paired compartment and the saline-paired compartment was used as the preference measure (thus, for animals conditioned in the initially non-preferred compartment, the initial preference is seen as a negative number; for animals conditioned in the initially preferred compartment the initial preference is seen as a positive number). This method of preference determination, which has been used in a number of studies (Mucha et al. 1982, 1985; Mucha and Iversen 1984; Mucha and Herz 1985; Bechara et al. 1987; Shippenberg and Herz 1987; Shippenberg et al. 1988, 1989; Bechara and van der Kooy 1989), offers an excellent graphical and statistical representation of preference and aversion in the shutthe box. Group means were obtained, and overall significance determined by two-factor repeated measures analysis of variance (drug treatment versus test day) where applicable. For individual treatments the preconditioned preference (or initial preference) was compared to the post-conditioned preference by a paired $t$-test. Differences between saline and drug treatments, or between different drug treatments, were compared using unpaired $t$-tests, or oneway analysis of variance followed by Dunnett's $t$-test. Reinforcing or aversive properties were determined by the ability of a drug to reverse or strengthen the initial preference of the animals for the drug-paired compartment. In addition to preference determinations, the number of entries into each compartment was quantified as a measure of locomotor activity within the apparatus.

\section{Results}

In the present studies an "unbiased" or "balanced" shuttle box was used. Although each rat individually had an initial bias, there was no overwhelming preference for one compartment over the other. This is reflected by the fact that approximately half the rats used in these experiments preferred the black compartment $(77 / 141=55 \%)$, and approximately half preferred the white compartment $(64 / 141=45 \%)$ prior to conditioning.

Two factor repeated measures analysis of variance of experiment 1 a revealed a significant effect of drug treatment $(P<0.01)$, a significant effect of test day $(P<$ $0.001)$, and a non-significant interaction $(P=0.06)$. Amphetamine, paired with the initially non-preferred compartment, caused a significant shift in preference to this compartment (preconditioning $=-182.1 \pm 45.5$, postconditioning $=203.3 \pm 72.2, n=9, P<0.001)$. This preference was maintained when animals were retested after 7 unhandled days in their home cages $(7$ days $=222.3 \pm$

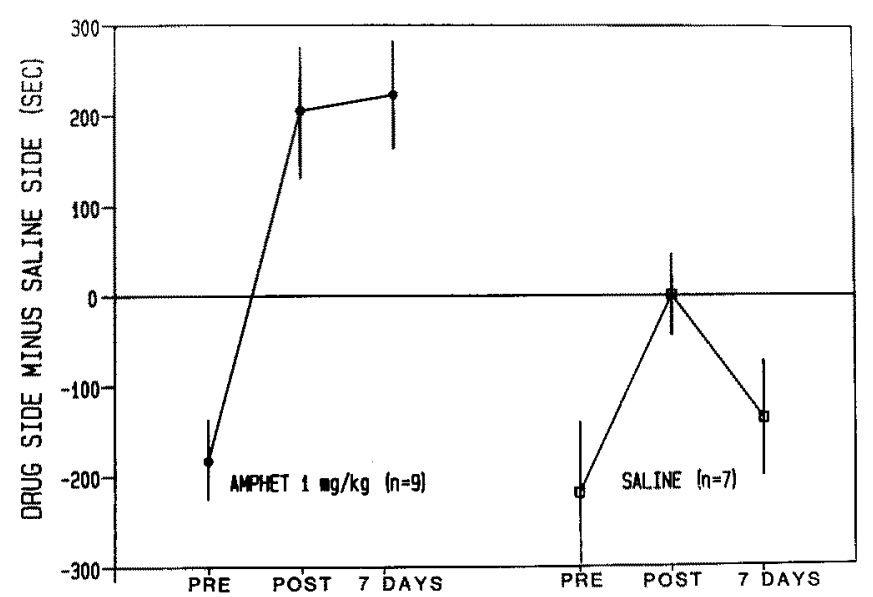

Fig. 1. Effects of amphetamine and saline in place conditioning. Amphetamine (AMPHET) paired with the initially non-preferred compartment caused animals to shift their preference to this compartment. Animals retained this altered preference when retested 7 days later. Saline paired with both compartments caused a nonsignificant shift to a non-preference for either compartment, which was not retained when animals were retested 7 days later. Scores represent number of seconds in the drug-paired compartment minus number of seconds in the saline-paired compartment (for saline animals, the initially non-preferred compartment was designated as the drug-paired compartment). $P R E=$ preconditioning preference; $P O S T=$ postconditioning preference

59.1; Fig. 1). Saline, paired with both compartments caused a non-significant shift to a non-preference for either compartment; i.e., a preference of zero (preconditioning $=-217.9 \pm 77.4$, postconditioning $=0.6 \pm 46.4$, $n=7$, n.s.). When retested after 7 days, there was a tendency for saline animals to return to preconditioned preferences, although the effect was not significant ( 7 days $=-138.0 \pm 64.6 ;$ Fig. 1 ). Unpaired $t$-test analyses of the saline and amphetamine group showed no significance difference between the groups at the preconditioning test, but a significant difference at the first postconditioning test $(P<0.025)$, and at the 7 -day test $(P<0.005)$. These experiments were highly replicable - effects in experiment $1 \mathrm{~b}$ were nearly identical to those in experiment 1 a [two-factor repeated measures ANOVA: drug treatment $(P<0.001)$, test day $(P<0.002)$, interaction $(P<$ $0.002)$; paired $t$-test analysis of drug treatments: amphetamine preconditioning $=-135.6 \pm 27.5$, postconditioning $=189.4 \pm 55.3, n=10, P<0.001$; saline preconditioning $=-115.2 \pm 6.3, \quad$ postconditioning $=-20.6 \pm$ $51.8, n=8$, n.s.; Fig. 2). When amphetamine was paired with the initially preferred compartment, no shift in preference was observed; animals maintained their preference for this compartment (preconditioning $=167.9 \pm$ 36.9 , postconditioning $=168.1 \pm 41.9, \quad n=16, \quad$ n.s.; Fig. 2), demonstrating that they preferred the compartment associated with amphetamine whether it was the initially non-preferred compartment or the initially preferred compartment. Comparison of the three drug treatments on the postconditioning day (one-way ANOVA, followed by Dunnett's $t$-test) revealed that the saline group was significantly different from amphetamine, whether amphetamine was paired with the initially non- 


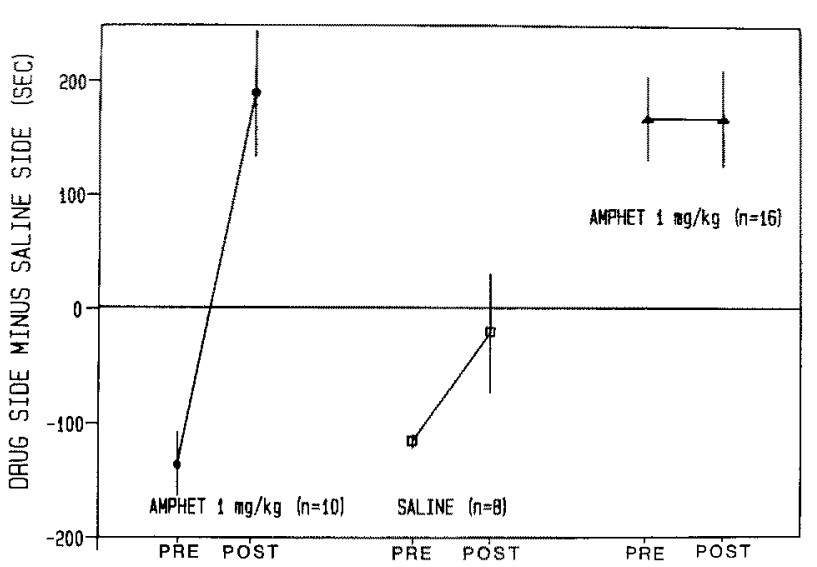

Fig. 2. Replicability of amphetamine and saline in place conditioning; effects of amphetamine conditioned in the initially preferred compartment. The effects of amphetamine ( $A M P H E T$ ) paired with the non-preferred compartment, and saline paired with both compartments were qualitatively and quantitatively very similar to those seen in Fig. 1 - amphetamine caused a significant shift to the drug-paired compartment, while saline caused a non-significant shift to a non-preference for either compartment. When amphetamine was paired with the initially preferred compartment, animals maintained their preference for this compartment. Scores represent number of seconds in the drug-paired compartment minus number of seconds in the saline-paired compartment (for saline animals, the initially non-preferred compartment was designated as the drug-paired compartment). $P R E=$ preconditioning preference; $P O S T=$ postconditioning preference

preferred compartment $(P<0.025)$ or paired with the initially preferred compartment $(P<0.025)$.

Naloxone caused a shift in preference away from the initially preferred compartment (Fig. 3). Two factor repeated measures analysis of variance showed no significant effect of treatment, a highly significant effect of test day $(P<0.001)$, and a significant interaction $(P<$ 0.005 ). While $0.02 \mathrm{mg} / \mathrm{kg}$ naloxone, paired with the initially preferred compartment, did not cause a significant shift in preference (preconditioning $=98.0 \pm 23.0$, postconditioning $=10.4 \pm 46.3, n=8$, n.s.), $0.2 \mathrm{mg} / \mathrm{kg}$ and $2.0 \mathrm{mg} / \mathrm{kg}$ produced successively greater shifts in preference away from this compartment $(0.2 \mathrm{mg} / \mathrm{kg}$ preconditioning $=222.8 \pm 80.4, \quad$ postconditioning $=-135.0 \pm$ 103.7, $\quad n=8, \quad P<0.05 ; \quad 2.0 \mathrm{mg} / \mathrm{kg}$ preconditioning $=$ $237.0 \pm 84.8, \quad$ postconditioning $=-325.2 \pm 74.2, \quad n=8$, $P<0.001$ ), although the difference between 0.2 and $2.0 \mathrm{mg} / \mathrm{kg}$ was not statistically significant. Naloxone $(2.0 \mathrm{mg} / \mathrm{kg})$ paired with the initially non-preferred compartment caused this compartment to be even less preferred, demonstrating that this drug produces aversion independent of the side of conditioning (preconditioning $=-235.8 \pm 92.6$, postconditioning $=-357.2 \pm 89.4$, $n=8, P<0.02$ ).

Animals conditioned with the combination of amphetamine $(1.0 \mathrm{mg} / \mathrm{kg})$ plus naloxone $(0.02,0.2$ or $2.0 \mathrm{mg} / \mathrm{kg}$ ) in the initially non-preferred compartment showed no significant change in preference (amphetamine $1.0 \mathrm{mg} / \mathrm{kg}$ plus naloxone 2.0 preconditioning = $-156.3 \pm 54.2$, postconditioning $=-103.6 \pm 72.2, \quad n=$ 11 , n.s.; amphetamine 1.0 plus naloxone 0.2 precondi-

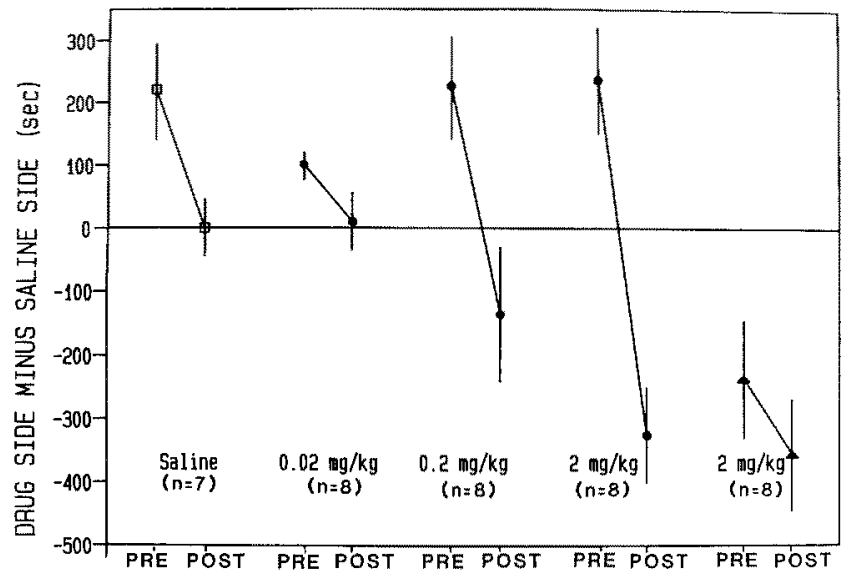

Fig. 3. Naloxone causes a dose-dependent place aversion. Saline data is the same as seen in Fig. 1, inverted for comparison with the naloxone scores (when saline is injected in both compartments, either compartment may be designated as the "drug side"). The saline data is shown for visual comparison only - these data were not included in the statistical analysis. Naloxone $0.02 \mathrm{mg} / \mathrm{kg}$ paired with the initially preferred compartment did not cause a significant shift in preference. Naloxone $0.2 \mathrm{mg} / \mathrm{kg}$ and naloxone $2.0 \mathrm{mg} / \mathrm{kg}$ paired with the initially preferred compartment each caused a significant shift in preference away from this compartment. Naloxone $2.0 \mathrm{mg} / \mathrm{kg}$ paired with the initially non-preferred compartment caused this compartment to be even less preferred. Scores represent number of seconds in the drug-paired compartment minus number of seconds in the saline-paired compartment. $P R E=$ preconditioning preference; $P O S T=$ postconditioning preference

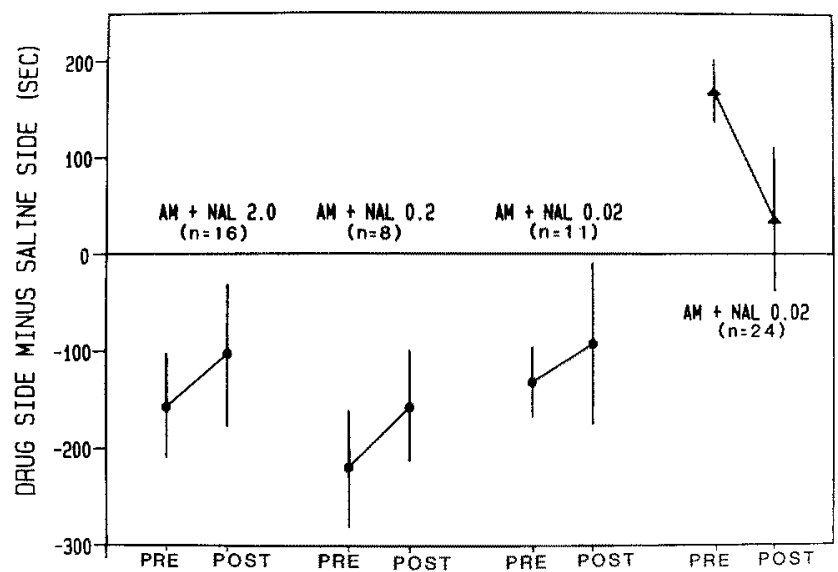

Fig. 4. Naloxone prevents the ability of amphetamine to cause a shift in place preference. When amphetamine $(A M)$ and naloxone $(N A L)$, administered together in a single injection, were paired with the initially non-preferred compartment, a non-significant shift toward a non-preference for either compartment was observed. When amphetamine and $0.02 \mathrm{mg} / \mathrm{kg}$ naloxone were paired with the initially preferred compartment, a non-significant shift toward a non-preference for either compartment was observed. Scores represent number of seconds in the drug-paired compartment minus number of seconds in the saline-paired compartment. $P R E=$ preconditioning preference $; P O S T=$ postconditioning preference

tioning $=-219.6 \pm 60.0, \quad$ postconditioning $=-157.1 \pm$ $57.0, n=8$, n.s.; amphetamine 1.0 plus naloxone 0.02 preconditioning $=-133.1 \pm 35.8$, postconditioning $=-$ $92.5 \pm 82.2, n=16$, n.s.), suggesting that naloxone interferes with the ability of amphetamine to produce a place 
Table 1. Effects of place conditioning on locomotor behavior. Values represent the mean number of entries \pm SEM into the drugpaired and saline-paired compartments, before and after conditioning, for each experimental treatment. The compartment which was paired with drug is shown in column 2: NPref=drug was paired with the initially non-preferred compartment; Pref=drug was paired with the initially preferred compartment (in the saline control experiment, saline was paired with both compartments, however the initially non-preferred compartment is designated as the drug-paired compartment). The number of animals is shown in parentheses. Numbers in brackets represent the postconditioning locomotor behavior expressed as percent of preconditioning. * Significant difference ( $P<0.05$, paired $i$-test) in locomotor behavior between the preconditioning test (pre) and the postconditioning test (post). $\uparrow$ Significant difference $(P<0.05$, paired t-test) between the drug-paired and saline-paired compartments at postconditioning test

\begin{tabular}{|c|c|c|c|c|}
\hline Treatment & $\begin{array}{l}\text { Conditioned } \\
\text { compartment }\end{array}$ & & Drug & Saline \\
\hline Saline & $\begin{array}{l}\text { Both } \\
(n=16)\end{array}$ & $\begin{array}{l}\text { Pre } \\
\text { Post }\end{array}$ & $\begin{array}{l}14.1 \pm 1.4 \\
17.3 \pm 2.6[122]\end{array}$ & $\begin{array}{l}14.8 \pm 1.3 \\
17.7 \pm 2.3[120]\end{array}$ \\
\hline \multirow[t]{2}{*}{ Amphetamine 1.0} & $\begin{array}{l}\text { NPref } \\
(n=19)\end{array}$ & $\begin{array}{l}\text { Pre } \\
\text { Post }\end{array}$ & $\begin{array}{l}13.5 \pm 1.1 \\
17.2 \pm 1.2[127]^{*}\end{array}$ & $\begin{array}{l}15.7 \pm 0.8 \\
15.0 \pm 1.1[96]\end{array}$ \\
\hline & $\begin{array}{l}\text { Pref } \\
(n=16)\end{array}$ & $\begin{array}{l}\text { Pre } \\
\text { Post }\end{array}$ & $\begin{array}{l}15.7 \pm 1.7 \\
22.5 \pm 2.4[143]^{*}\end{array}$ & $\begin{array}{l}11.6 \pm 1.6 \\
19.6 \pm 3.7[169]^{*}\end{array}$ \\
\hline Naloxone 0.02 & $\begin{array}{l}\text { Pref } \\
(n=8)\end{array}$ & $\begin{array}{l}\text { Pre } \\
\text { Post }\end{array}$ & $\begin{array}{l}11.2 \pm 1.4 \\
16.6 \pm 2.7[148]\end{array}$ & $\begin{array}{l}11.9 \pm 1.3 \\
18.6 \pm 3.6[156]\end{array}$ \\
\hline Naloxone 0.2 & $\begin{array}{l}\text { Pref } \\
(n=8)\end{array}$ & $\begin{array}{l}\text { Pre } \\
\text { Post }\end{array}$ & $\begin{array}{l}10.6 \pm 2.0 \\
10.0 \pm 2.2[94]\end{array}$ & $\begin{array}{l}10.0 \pm 2.1 \\
15.5 \pm 3.8[155]\end{array}$ \\
\hline Naloxone 2.0 & $\begin{array}{l}\text { Pref } \\
(n=8)\end{array}$ & $\begin{array}{l}\text { Pre } \\
\text { Post }\end{array}$ & $\begin{array}{l}14.1 \pm 2.0 \\
4.8 \pm 1.2[34] *\end{array}$ & $\begin{array}{l}11.6 \pm 2.1 \\
14.6 \pm 3.6[126]+\end{array}$ \\
\hline Am $1.0+\mathrm{Nal} 0.02$ & $\begin{array}{l}\text { NPref } \\
(n=16)\end{array}$ & $\begin{array}{l}\text { Pre } \\
\text { Post }\end{array}$ & $\begin{array}{l}14.5 \pm 2.2 \\
13.2 \pm 2.4[91]\end{array}$ & $\begin{array}{l}15.1 \pm 1.7 \\
15.6 \pm 1.8[103]\end{array}$ \\
\hline Am $1.0+\mathrm{Nal} 0.2$ & $\begin{array}{l}\text { NPref } \\
(n=8)\end{array}$ & $\begin{array}{l}\text { Pre } \\
\text { Post }\end{array}$ & $\begin{array}{l}9.9 \pm 1.9 \\
11.2 \pm 1.1[113]\end{array}$ & $\begin{array}{l}14.9 \pm 3.0 \\
19.2 \pm 2.7[129] * \dagger\end{array}$ \\
\hline $\mathrm{Am} 1.0+\mathrm{Na} 12.0$ & $\begin{array}{l}\text { NPref } \\
(n=11)\end{array}$ & $\begin{array}{l}\text { Pre } \\
\text { Post }\end{array}$ & $\begin{array}{l}13.5 \pm 2.6 \\
8.3 \pm 1.8[61]\end{array}$ & $\begin{array}{l}16.5 \pm 3.1 \\
14.3 \pm 1.9[87]+\end{array}$ \\
\hline
\end{tabular}

preference (Fig. 4). Note that even the lowest dose of naloxone $(0.02 \mathrm{mg} / \mathrm{kg})$, which lacked aversive effects on its own, still had the ability to block the place conditioning effects of amphetamine. When the combination of $0.02 \mathrm{mg} / \mathrm{kg}$ naloxone plus $1.0 \mathrm{mg} / \mathrm{kg}$ amphetamine was injected in the initially preferred compartment, the results were very similar to saline conditioning; the shift was toward a non-preference for either compartment (preconditioning $=168.9 \pm 31.5, \quad$ postconditioning $=$ $37.1 \pm 74.3, n=24$, n.s.; Fig. 4 ). There was no significant difference between any of the treatments at the postconditioning test.

In the present studies we assessed locomotor activity by measuring compartment entries during testing, both before and after conditioning. The number of compartment entries is not only a good measure of locomotor activity within the shuttle box, but also an excellent measure of activity within each compartment. This was demonstrated in a recent study by Neisewander et al. (1990), who found a very high correlation between the number of entries into a compartment and the number of line crossings within that compartment $(r=0.90, P<0.005$ for data shown in Table 1 of their paper). The effect of place conditioning on compartment entries for the present experiments are shown in Table 1 . The general tendency observed was a non-significant increase in total entries for most treatments, including saline control animals. These increases were typically observed in both the drug-paired and saline-paired compartments, suggesting that conditioning may lead to a mild, non-selective increase in locomotor activity within the shuttle box. Significant increases in entries into the drug-paired compartment were observed when amphetamine was paired with the initially non-preferred compartment, into both compartments when amphetamine was paired with the initially preferred compartment, and into the salinepaired compartment when amphetamine and naloxone $(0.2 \mathrm{mg} / \mathrm{kg})$ were paired with the initially non-preferred compartment. By far, the most robust effect on compartment entries was in naloxone-treated animals. The highest dose of naloxone $(2.0 \mathrm{mg} / \mathrm{kg})$ produced significant decreases in compartment entries when paired with either the initially preferred or the initially non-preferred compartment. The only treatments which produced significant differences in compartment entries between the drug-paired and saline paired compartments were naloxone $(2.0 \mathrm{mg} / \mathrm{kg})$ paired with either compartment, and naloxone $(0.2$ or $2.0 \mathrm{mg} / \mathrm{kg})$ and amphetamine paired with the initially non-preferred compared. In each of these cases the drug-paired compartment had signifi- 
cantly fewer entries than the saline-paired compartment. Thus, beyond the decrease in entries into the drug-paired compartment for animals receiving high doses of naloxone, these results demonstrate no consistent relationship between locomotor activity and place conditioning.

\section{Discussion}

Repeated pairings of a distinctive environment with amphetamine caused animals to prefer that environment over an alternative environment associated with saline, confirming previous reports of the effects of amphetamine in place conditioning (see Carr et al. 1989; Hoffman 1989 for review). The place conditioning produced by amphetamine was both highly replicable and persistent, remaining at least 7 days after conditioning. Moreover, when amphetamine was paired with the initially preferred compartment, this compartment was still preferred after conditioning. These results demonstrate that amphetamine did not cause a non-specific shift in preference, but instead that animals preferred the compartment associated with this drug regardless of whether the compartment was the initially preferred or the initially non-preferred environment. Although amphetamine did not produce an increase in preference for the initially preferred compartment, evidence suggests that the results represent a valid conditioned place preference; 1) in contrast to saline control groups a strong preference was maintained for the drug-paired compartment after conditioning, 2) the magnitude of the post-conditioning preference score was virtually identical to the score for animals conditioned with amphetamine in the initially non-preferred compartment, and 3) the results for these animals were significantly different from saline. Thus, although no increase in preference was observed for animals conditioned with amphetamine in the initially preferred compartment, the fact that the preference score remained highly positive is significant.

Interestingly, when saline was paired with both compartments, a slight, non-significant shift in preference was observed. However, this shift was not a change in preference to the opposite compartment as seen with amphetamine, but a shift to a non-preference for either compartment; i.e. a preference of zero. Although the shift was not significant in either experiment, evidence suggests that the effect is reliable. First, when the data for the two saline experiments is combined, the effect closely approaches statistical significance $(P=0.06)$. Second, a similar non-significant shift was observed in animals treated with the low dose of naloxone $(0.02 \mathrm{mg} / \mathrm{kg})$ when this dose was administered alone, or when it was administered with amphetamine. The elimination of unconditioned biases with saline or very low doses of naloxone may represent habituation of the animals to the two compariments. Each animal, in the course of the experiments, was confined to each compartment for four 30 -min sessions. This confinement may have led to habituation of those cues that caused the animal to prefer one environment over the other prior to injections. It is interesting to note that there was a tendency for salinetreated animals to return to preconditioned preferences when retested 7 days later. It may be that a week without exposure to the apparatus allows the extinction of habituation and the reestablishment of unconditioned preferences. Future studies should help to elucidate the reliability and significance of the effects seen in animals receiving saline in both compartments.

Naloxone, in the present studies, caused animals to avoid the compartment associated with this drug, in a dose-dependent manner. While the effects of $0.02 \mathrm{mg} / \mathrm{kg}$ were similar to those of saline, the higher doses produced significant place aversions. In parallel with the amphetamine experiments, conditioning occurred independent of which compartment was paired with drug - animals avoided the naloxone-paired compartment whether this drug was paired with the initially preferred environment or the initially non-preferred environment, suggesting that this effect was a specific place aversion, rather than a non-specific change in compartment preference. In previous studies, conflicting results have been reported, with some studies observing place aversion with naloxone (Mucha et al. 1982, 1985; Mucha and Iversen 1984; Bechara and van der Kooy 1985; Mucha and Herz 1985), and other studies obtaining no effects of this drug in place conditioning (Phillips and LePiane 1980, 1982; Bozarth and Wise 1981). It has been suggested that the lack of effects in the latter studies resulted from insensitive procedures used by the investigators (Mucha and Iversen 1984). Significantly, the effects observed for naloxone in the present experiments were strikingly similar to those reported in two previous studies (Mucha et al. 1982; Mucha and Iversen 1984).

Animals injected with combinations of amphetamine plus naloxone in the initially non-preferred compartment showed no significant change in place preference, in an apparent blockade of amphetamine place conditioning by naloxone. However, since the 0.2 and $2.0 \mathrm{mg} / \mathrm{kg}$ doses of naloxone alone produced place aversions, it cannot be concluded that these doses simply blocked amphetamine conditioning - the interaction may have resulted from an algebraic summation of the negative effects of naloxone and the positive effects of amphetamine in place conditioning. On the other hand, since no aversive effects were detected with $0.02 \mathrm{mg} / \mathrm{kg}$ naloxone, it appears that this dose selectively blocked the place conditioning actions of amphetamine. An alternate possibility is that the combination of naloxone plus amphetamine was aversive to the animals. Despite the lack of effect of $0.02 \mathrm{mg} / \mathrm{kg}$ naloxone alone in place conditioning, it is possible that this dose in combination with amphetamine was aversive. However, animals conditioned with this combination showed effects very similar to saline - a shift toward a non-preference for either compartment, regardless of whether the conditioning took place in the initially preferred or the initially non-preferred compartment. The fact that these effects were very similar to those of saline suggests that the low dose of naloxone produced a simple blockade of amphetamine-dependent place conditioning. It is important to emphasize the low dose required for this blockade. The $0.02 \mathrm{mg} / \mathrm{kg}$ dose of naloxone is 10 fold less than the dose required to suppress self-stimulation behavior (Trujillo et al. 
$1983,1989 \mathrm{a}, \mathrm{b})$, and 500 fold less than the dose required to suppress locomotion (DeRossett and Holtzman 1982).

As noted above, results in place conditioning experiments are commonly interpreted as reflecting the rewarding or aversive properties of the drug(s) under study. It has been suggested, however, that the place conditioning paradigm may be confounded for drugs, such as amphetamine, which alter locomotor behavior (Swerdlow and Koob 1984). According to this suggestion, the amphetamine place preference observed in the present study may have been an artifact of increased locomotion in the drug-paired compartment. Moreover, the blockade of amphetamine place preference by naloxone may have resulted from naloxone blockade of amphetamine-dependent locomotion (Hitzemann et al. 1982; Holtzman 1974; Swerdlow et al. 1985). Several studies, however, have demonstrated that locomotor activity does not contribute significantly to place preference conditioning, and thereby dispute the suggestion that drug-induced place preferences are artifacts of alterations in locomotion (DiScala et al. 1985; Martin-Iverson et al. 1985; Mithani et al. 1986; Bozarth 1987; Vezina and Stewart 1987; Carr et al. 1988, 1989; Costello et al. 1989; Shippenberg et al. 1989). In the present studies we measured locomotion in the shuttle box during testing and found no consistent relationship between this behavior and amphetamine-induced changes in place preference. Although the present data cannot completely rule out the possibility that the place conditioning resulted from drug-induced changes in locomotion, the above noted studies, together with our data on locomotor behavior, support our suggestion that the present results are indeed a valid reflection of the motivational properties of amphetamine and naloxone, rather than a locomotor artifact. Further, although it is presently unclear whether the place conditioning paradigm measures the same aspects of reward as the self-administration or self-stimulation experiments, most investigators agree that this methodology is a legitimate tool for examining the rewarding properties of drugs (Bozarth 1987; van der Kooy 1987; Carr et al. 1989; Hoffman 1989).

Regarding possible explanations for the blockade of amphetamine reward by naloxone, it must first be considered that this effect might result from a non-specific chemical or pharmacokinetic interaction; i.e., naloxone might alter the absorption or distribution of amphetamine in the body, preventing this drug from reaching the brain. If such a mechanism were responsible for the effects of naloxone, then one might predict that this drug should similarly affect different psychoactive actions of amphetamine. However, naloxone has been reported to affect some of amphetamine's actions but not others. Holtzman (1974) observed that naloxone reduced the stimulatory effects of amphetamine on avoidance responding and locomotor activity, but not amphetamine's effects on food intake or body temperature. Likewise, Haber and coworkers (Haber et al. 1978), and Hitzemann et al. (1982) observed that naloxone selectively blocked amphetamine-stimulated rearing behavior without affecting amphetamine-dependent hyperactivity or stereotypy. In addition, naloxone has been observed to attenuate amphetamine-dependent facilitation of dorsal tegmental self-stimulation, but not self-stimulation of the prefrontal cortex (Franklin and Robertson 1982). It should be noted that different actions of naloxone on different amphetamine-dependent behaviors does not unequivocally rule out a non-specific pharmacokinetic interaction. For example, if naloxone simply decreased the concentration of amphetamine reaching the brain, then this drug might interfere with behaviors dependent on a high dose of amphetamine, but not behaviors requiring a low dose. Nevertheless, the fact that naloxone interferes with very closely related behavioral actions of amphetamine, i.e. amphetamine-dependent rearing, but not hyperactivity or stereotypy, and selectively attenuates the effects of amphetamine on self-stimulation of one brain site but not another, lead us to believe that the present results were not due to a non-specific pharmacokinetic interaction. Moreover, if naloxone non-specifically interfered with the absorption or distribution of amphetamine in the body, then one might expect that this drug would also affect the pharmacokinetics of a variety of other drugs. However, the effects of naloxone are limited to remarkably few actions and interactions (cf. Andrews and Holtzman 1988). Naloxone blockade of amphetamine place conditioning, therefore, more likely results from a specific neural interaction between these drugs.

Although the site of interaction between naloxone and amphetamine is presently unknown, evidence suggests that the nucleus accumbens is a likely candidate. Studies suggest that amphetamine has its reinforcing action by releasing dopamine from mesolimbic nerve terminals in this nucleus (Lyness et al. 1979; Monaco et al. 1981; Spyraki et al. 1982 b; Aulisi and Hoebel 1983). Additionally, receptor binding studies have demonstrated that opioid receptors are located on mesolimbic dopamine neurons (Pollard et al. 1977). Naloxone has been observed to antagonize the amphetamine-stimulated release of ${ }^{3} \mathrm{H}$-dopamine (Hitzemann et al. 1982), and the amphetamine-dependent decrease of the dopamine metabolite, homovanillic acid, in the nucleus accumbens (Applegate et al. 1982). Therefore, naloxone may prevent amphetamine reward by blocking opiate receptors on mesolimbic dopamine neurons, interfering with amphetamine-stimulated release of dopamine. Regardless of the specific neural mechanism responsible, however, the present results demonstrate that activation of opioid receptors may play an important role in the ability of amphetamine to establish a conditioned place preference.

It is notable that opiate antagonists have been observed to interfere with amphetamine in a variety of behavioral tests, including continuous avoidance responding and locomotor activity (Holtzman 1974; Swerdlow et al. 1985; Andrews and Holtzman 1987; Winslow and Miczek 1988), rearing behavior (Haber et al. 1978; Hitzemann et al. 1982), turning behavior (Dettmar et al. 1978), and acquisition and consolidation of memory (Fulginiti and Cancela 1983). More important to the present results, however, are findings of interactions be- 
tween naloxone and amphetamine in self-stimulation experiments. Several investigators have reported that naloxone prevents the facilitating effect of amphetamine on self-stimulation, suggesting that blockade of opioid receptors intereferes with the reinforcing actions of amphetamine (Holtzman 1976; Esposito et al. 1980; Leith 1982; Trujillo et al. 1983). The present results support this possibility, providing further evidence that activation of opioid receptors may be necessary for amphetamine reinforcement. Interestingly, recent reports examining interactions between opiate antagonists and cocaine in self-administration (Carroll et al. 1986; De Vryet al. 1989), self-stimulation (Bain and Kornetsky 1986), and place conditioning (Houdi et al. 1989) suggest that blockade of opioid receptors may interfere with the reinforcing actions of cocaine. It thus appears that opioid receptors may play a general role in the rewarding actions of psychomotor stimulants. These findings provide an interesting contrast to studies which suggest that activation of dopamine systems is necessary for opioid reinforcement (Bozarth and Wise 1981; Spyraki et al. 1983; Shippenberg and Herz 1987; Hand et al. 1989). Despite studies demonstrating interactions between opioids and catecholamines in reward, however, other studies have found evidence against such interactions (e.g. Ettenberg et al. 1982; Mackey and van der Kooy 1985). Thus, although the evidence is not unanimous, the present results together with previous studies suggest that interactions between endogenous opioid and catecholamine systems may be important in the reinforcing actions of drugs. Further, these results hint that the neurochemistry of reward may be more complex than is currently believed.

In conclusion, the present results suggest that activation of opioid receptors is necessary for amphetamine's rewarding action. Amphetamine was observed to establish a potent conditioned place preference which could be prevented by the opiate receptor antagonist naloxone. This action of naloxone was determined to be independent of aversive effects of naloxone alone, or aversive interactions between amphetamine and naloxone, and thus appears to be a specific blockade of amphetamine reward. These results support previous studies demonstrating the ability of naloxone to block amphetamine facilitation of self-stimulation behavior (Holtzman 1976: Esposito et al. 1980; Leith 1982; Trujillo et al. 1983) and add to the increasing evidence that interactions between endogenous opioid and catecholamine systems are important in reinforcement. Moreover, in light of recent clinical findings demonstrating the potential efficacy of opiate antagonists in the treatment of cocaine abuse (Kosten et al. 1989) the present results are of particular interest, suggesting that opiate antagonists may also be effective pharmacological aids in the treatment of amphetamine abuse.

Acknowledgements. We would like to give many thanks to Peyman R. Tabrizi for his his superb animal-handling abilities, and his excellent assistance in helping to set up and perform these place preference experiments. We would like to thank Dr. J.P. Herman for his helpful comments on the revised manuscript.

\section{References}

Almaric M, Cline EJ, Martinez JL, Bloom FE, Koob GF (1987) Rewarding properties of beta-endorphin as measured by conditioned place preference. Psychopharmacology $91: 14-19$

Andrews JS, Holtzman SG (1987) Effects of naloxone and diprenorphine on amphetamine-stimulated behavior in guinea pigs and rats. Neuropharmacology 26:1115-1120

Andrews IS, Holtzman SG (1988) Effects of $d$-amphetamine, morphine, naloxone, and drug combinations on visual discrimination in rats. Psychopharmacology 94:172-177

Applegate CD, Kuczenski R, Leith NJ (1982) Naloxone-amphetamine interactions: biochemical effects in dopamine terminal regions. Soc Neurosci Abstr 8:121

Aulisi, EF, Hoebel BG (1983) Rewarding effects of amphetamine and cocaine in the nucleus accumbens and blockade by flupenthixol. Soc Neurosci Abstr 9:121

Bain GT, Kornetsky C (1986) Naloxone attenuation of the effect of cocaine on rewarding brain stimulation. Life Sci 40:11191125

Bechara A, van der Kooy D (1985) Opposite motivational effects of endogenous opioids in brain and periphery. Nature 314:533534

Bechara A, Zito KA, van der Kooy D (1987) Kappa receptors mediate the peripheral aversive effects of opiates. Pharmacol Biochem Behav 28:227-233

Bechara A, van der Kooy D (1989) The tegmental pedunculopontine nucleus: a brain-stem output of the limbic system critical for the conditioned place preferences produced by morphine and amphetamine. I Neurosci 9:3400-3409

Belluzzi JD, Stein L (1977) Enkephalin may mediate euphoria and drive-reduction reward. Nature 266:556-558

Bozarth MA (1983) Opiate reward mechanisms mapped by intracranial self-administration. In: Smith JE, Lane JD (eds) The Neurobiology of opiate reward processes. Elsevier, New York, pp 331-360

Bozarth MA (1987) Conditioned place preference: a parametric analysis using systemic heroin injections. In: Bozarth MA (ed) Methods of assessing the reinforcing propertics of abused drugs. Springer, Berlin Heidelberg New York, pp 241-274

Bozarth MA, Wise RA (1981) Heroin reward is dependent on a dopaminergic substrate. Life Sci 29:1881-1886

Broekkamp CLE, Phillips AG, Cools AR (1979) Facilitation of self-stimulation behavior following intracerebral microinjections of opioids into the ventral tegmental area. Pharmacol Biochem Behav 11:289-295

Carboni E, Acquas E, Leone P, Di Chiara G (1989) $5 \mathrm{HT}_{3}$ receptor antagonists block morphine- and nicotine- but not amphetamine-induced reward. Psychopharmacology 97:175-178

Carr GD, Phillips AG, Fibiger HC (1988) Independence of amphetamine reward from locomotor stimulation demonstrated by conditioned place preference. Psychopharmacology 94:221-226

Carr GD, Fibiger HC, Phillips AG (1989) Conditioned place preference as a measure of drug reward. In: Liebman JM, Cooper SJ (eds) The Neuropharmacological basis of reward. Oxford, New York, pp 264-319

Carroll ME, Lac ST, Walker MJ, Kragh R, Newman T (1986) Effects of naltrexone on intravenous cocaine self-administration in rats during food satiation and deprivation. J Pharmacol Exp Ther $238 ; 1-7$

Costello NL, Carlson JN, Glick SD, Bryda M (1989) Dose-dependent and baseline-dependent conditioning with $d$-amphetamine in the place conditioning paradigm. Psychopharmacology $99: 244-247$

Davis WM, Smith SG (1973) Blocking of morphine based reinforcement by alpha-methyltyrosine. Life Sci 12:185-181

DeRossett SE, Holtzman SG (1982) Effects of naloxone and diprenorphine on spontaneous activity in rats and mice. Pharmacol Biochem Behav 17:347-351

De Vry J, Donselaar I, Van Ree JM (1989) Food deprivation and 
acquisition of intravenous cocaine self-administration in rats: effect of naltrexone and haloperidol. $J$ Pharmacol Exp Ther $251: 735-740$

Dettmar PW, Cowan A, Walter DS (1978) Naloxone antagonizes behavioral effects of $d$-amphetamine in mice and rats. Neuropharmacology 17:1041-1044

DiScala G, Martin-Iverson MT, Phillips AG, Fibiger HC (1985) The effects of progabide (SL 76002) on locomotor activity and conditioned place preference induced by $d$-amphetamine. Eur J Pharmacol 107:271-274

Esposito RU, Perry W, Kornetsky C (1980) Effects of $d$-amphetamine and naloxone on brain stimulation reward. Psychopharmacology $69: 187-191$

Esposito RU, Perry W, Kornetsky C (1981) Chlorpromazine and brain-stimulation reward: potentiation of effects by naloxone. Pharmacol Biochem Behav 15:903-905

Ettenberg A, Pettit HO, Bloom FE, Koob GF (1982) Heroin and cocaine intravenous self-administration in rats mediation by separate neural systems. Psychopharmacology 78:204-209

File SE (1986) Aversive and appetitive properties of anxiogenic and anxiolytic agents. Behav Brain Res 21:189-194

Franklin KBG, Robertson A (1982) Effects and interactions of naloxone and amphetamine on self-stimulation of the prefrontal cortex and dorsal tegmentum. Pharmacol Biochem Behav $16: 433-436$

Fudala PJ, Teoh KW, Iwamoto ET (1985) Pharmacologic characterization of nicotine-induced conditioned place preference. Pharmacol Biochem Behav 22:237-241

Fulginiti S, Cancela LM (1983) Effects of naloxone and amphetamine on acquisition and memory consolidation of active avoidance responses in rats. Psychopharmacology 79:45-48

Gilbert D, Cooper SJ (1983) $\beta$-phenylethylamine-, $d$-amphetamineand $l$-amphetamine-induced place preference conditioning in rats. Eur J Pharmacol 95:311-314

Glimcher PW, Giovino AA, Margolin DH, Hoebel BG (1984a) Endogenous opioid reward induced by an enkephalinase inhibitor, thiorphan, injected into the ventral midbrain. Behav Neurosei $98: 262-268$

Glimcher PW, Margolin DH, Giovino AA, Hoebel BG (1984b) Neurotensin: a new 'reward peptide'. Brain Res 291:119-124

Haber, S, Hatsukami T, Berger PA, Barchas JD, Akil H (1978) Naloxone blocks amphetamine-induced rearing: potential interaction between catecholamines and endorphins. Prog Neuropsychopharmacol Biol Psychiatry 2:425 430

Hand TH, Stinus L, Le Moal M (1989) Differential mechanisms in the acquisition and expression of heroin-induced place preference. Psychopharmacology 98:61-67

Hitzemann R, Curell J, Hom D, Loh H (1982) Effects of naloxone on $d$-amphetamine- and apomorphine-induced behavior. Neuropharmacology $21: 1005-1011$

Hoffman DC (1989) The use of place conditioning in studying the neuropharmacology of drug reinforcement. Brain Res Bull $23: 373-387$

Holtzman Sg (1974) Behavioral effects of separate and combined administration of naloxone and $d$-amphetamine. J Pharmacol Exp Ther 180:51-60

Holtzman SG (1976) Comparison of the effects of morphine, pentazocine, cyclazocine and amphetamine on intracranial self-stimulation in the rat. Psychopharmacology 46:223-227

Houdi AA, Bardo MT, Van Loon GR (1989) Opioid mediation of cocaine-induced hyperactivity and reinforcement. Brain Res 497:195-198

Hubner CB, Bain GT, Kornetsky C (1987) The combined effect of morphine and $\mathrm{d}$-amphetamine on the threshold for brain stimulation reward. Pharmacol Biochem Behav 28:311-315

Katz RJ, Gormenzano G (1979) A rapid and inexpensive technique for assessing the reinforcing effects of opiate drugs. Pharmacol Biochem Behav 11:231-234

Kosten TR, Kleber HD, Morgan C (1989) Role of opioid antagonists in treating intravenous cocaine abuse. Life Sci 44:887892
Leith NJ (1982) Effects of clonidine and naloxone on self-stimulation responding before and after chronic amphetamine treatment. Soc Neurosci Abstr 8:103

Lyness W, Friedle N, Moore K (1979) Destruction of dopaminergic nerve terminals in nucleus accumbens: effects on $d$-amphetamine self-administration. Pharmacol Biochem Behav 11:553556

Mackey WB, van der Kooy D (1985) Neuroleptics block the positive reinforcing effects of amphetamine but not of morphine as measured by place conditioning. Pharmacol Biochem Behav 22:101-105

Maroli A, Tsang W-K, Stutz R (1978) Morphine and self-stimulation: evidence for action on a common neural substrate. Pharmacol Biochem Behav 8:119-123

Martin-Iverson MT, Ortmann R, Fibiger HC (1985) Place preference conditioning with methylphenidate and nomifensine. Brain $\operatorname{Res} 332: 59-67$

Mithani S, Martin-Iverson MT, Phillips AG, Fibiger HC (1986) The effects of haloperidol on amphetamine- and methylphenidate-induced conditioned place preferences and locomotor activity. Psychopharmacology 90:247-252

Monaco A, Hernandez L, Hoebel B (1981) Nucleus accumbens: site of amphetamine self-injection: comparison with the lateral ventrical. In: Chronister RB, DeFrance JF (ed) The neurobiology of the nucleus accumbens. Haer Institute, Brunswick, Maine, pp 338-342

Mucha RF, Herz A (1985) Motivational properties of kappa and $\mathrm{mu}$ opioid receptor agonists studied with place and taste preference conditioning. Psychopharmacology 86:274-280

Mucha RF, Iversen SD (1984) Reinforcing properties of morphine and naloxone revealed by conditioned place preferences: a procedural examination. Psychopharmacology 82:241-247

Mucha RF, van der Kooy D, O'Shaughnessy $M$, Bucenieks $P$ (1982) Drug reinforcement studied by use of place conditioning in rat. Brain Res $243: 91-105$

Mucha RF, Millan MJ, Herz A (1985) Aversive properties of naloxone in non-dependent (naive) rats may involve blockade of central $\beta$-endorphin. Psychopharmacology 86:281-285

Neisewander JL, Pierce RC, Bardo MT (1990) Naloxone enhances the expression of morphine-induced conditioned place preference. Psychopharmacology 100:201-205

Pert A, Hulsebus R (1975) Effect of morphine on intracranial selfstimulation behavior following brain amine depletion. Life Sci $17: 19-20$

Phillips AG, LePiane FG (1980) Reinforcing effects of morphine microinjection into ventral tegmental area. Pharmacol Biochem Behav 12:965-968

Phillips AG, LePiane FG (1982) Reward produced by microinjection of d-ala-met-enkephalinamide into the ventral tegmental area. Behav Brain Res 5:225-229

Phillips AG, Spyraki C, Fibiger HC (1982) Conditioned place preference with amphetamine and opiates as reward stimuli: attenuation by haloperidol. In: Hoebel BG, Novin D (eds) The neural basis of feeding and reward. Haer Institute, Brunswick, Maine, pp $455-464$

Pollard H, Llorens C, Bonnet JJ, Constentin J, Schwartz JC (1977) Opiate receptors on mesolimbic dopaminergic neurons. Neurosci Lett 7:295-299

Reicher MA, Holman EW (1977) Location preference and flavor aversion reinforced by amphetamine in rats. Anim Learn Behav $5: 343-346$

Rossi NA, Reid L (1976) Affective states associated with morphine injections. Physiol Psychol 4:269-274

Sherman JE, Roberts T, Roskam SE, Holman EW (1980) Temporal properties of the rewarding and aversive effects of amphetamine in rats. Pharmacol Biochem Behav 13:597--599

Shippenberg TS, Herz A (1987) Place preference conditioning reveals the involvement of D1-dopamine receptors in the motivational properties of $\mu$ and $\kappa$-opioid agonists. Brain Res 436: 169-172

Shippenberg TS, Emmett-Oglesby M, Ayesta J, Herz A (1988) Tol- 
erance and selective cross-tolerance to the motivational effects of opioids. Psychopharmacology 96:110-115

Shippenberg TS, Emmett-Oglesby MW, Herz A (1989) Morphineinduced place conditioning is not confounded by drug-induced alterations in locomotor activity. Pharmacol Biochem Behav $32: 129-132$

Spyraki C, Fibiger HC, Phillips AG (1982a) Cocaine-induced place preference conditioning: lack of effects of neuroleptics and 6hydroxydopamine lesions. Brain Res 253:195-203

Spyraki C, Fibiger HC, Phillips AG (1982b) Dopaminergic substrates of amphetamine-induced place preference conditioning. Brain Res 253:185-193

Spyraki C, Fibiger HC, Phillips AG (1983) Attenuation of heroin reward by disruption of the mesolimbic dopamine system. Psychopharmacology $79: 278-283$

Spyraki C, Kazandjian A, Varanos D (1985) Diazepam-induced place preference conditioning: appetitive and antiaversive properties. Psychopharmacology 87:225-232

Spyraki C, Nomikos GG, Varonos DD (1987) Intravenous cocaineinduced place preference: attenuation by haloperidol. Behav Brain Res 26:57-62

Spyraki C, Nomikos GG, Galanopoulou P, Daïfotis Z (1988) Drug-induced place preference in rats with 5,7-dihydroxytryptamine lesions of the nucleus accumbens. Behay Brain Res $29: 127-134$

Stapleton MJ, Lind MD, Merriman VJ, Bozarth MJ, Reid LF (1979) Affective consequences and subsequent effects on morphine self-administration of $d$-ala-methionine enkephalin. Physiol Psychol 7:146-152

Stein L (1978) Reward transmitters: catecholamines and opioid peptides. In: Lipton MA, DiMascio A, Killam KF (ed) Psychopharmacology: a generation of progress. Raven Press, New York, pp 569-581

Swerdlow NR, Koob GF (1984) Restrained rats learn amphetamine-conditioned locmotion, but not place preference. Psychopharmacology 84:163-166
Swerdlow NR, Vaccarino FJ, Koob GF (1985) Effects of naloxone on heroin-, amphetamine- and caffeine-stimulated locomotor activity in the rat. Pharmacol Biochem Behav 23:499501

Trujillo KA, Belluzzi JD, Stein L (1983) Endorphin-catecholamine interactions in nucleus accumbens self-stimulation. Soc Neurosci Abstr 9:277

Trujillo KA, Belluzzi JD, Tabrizi PR, Stein L (1985) Naloxone blockade of amphetamine reward in place preference conditioning. Soc Neurosci Abstr 11:1173

Trujillo KA, Belluzzi JD, Stein L (1989a) Effects of opiate antagonists and their quaternary analogues on nucleus accumbens selfstimulation. Behav Brain Res 33:181-188

Trujillo KA, Belluzzi JD, Stein L (1989b) Naloxone suppression of self-stimulation is independent of response difficulty. Pharmacol Biochem Behav 33:147-155

van der Kooy D (1987) Place conditioning: a simple and effective method for assessing the motivational properties of drugs. In: Bozarth MA (ed) Methods of assessing the reinforcing properties of abused drugs. Springer, Berlin Heidelberg New York, pp 229-240

van der Kooy D, Mucha RF, O'Shaughnessy $M$, Bucenieks $P$ (1982) Reinforcing effects of morphine revealed by conditioned place preference. Brain Res 243:107-117

Vezina P, Stewart J (1987) Morphine conditioned place preference and locomotion: the effect of confinement during training. Psychopharmacology $93: 257-260$

Watson SJ, Trujillo KA, Herman JP, Akil H (1989) Neuroanatomical and neurochemical substrates of drug seeking behavior: overview and future directions. In: Goldstein A (ed) Molecular and cellular aspects of the drug addictions. Springer, Berlin Heidelberg New York, pp 29-91

Winslow JT, Miczek KA (1988) Naltrexone blocks amphetamineinduced hyperactivity, but not disruption of social and agonistic behavior in mice and squirrel monkeys. Psychopharmacology $96: 493-499$ 